\title{
Citrus jabara Extracts Suppress MUC5AC Mucin Production in Human Lung Epithelial Cells
}

\author{
Jun Iwashita1 ${ }^{*}$, Naoki Iguchi', Akiko Takashima², Daisuke Watanabe ${ }^{2}$, Kimihiko Sano², \\ Masahiko Ishikuro ${ }^{3}$, Keishi Hata ${ }^{4}$, Jun Murata1
}

\author{
${ }^{1}$ Faculty of Bioresource Sciences, Akita Prefectural University, Akita, Japan \\ ${ }^{2}$ Sano Inc., Akita, Japan \\ ${ }^{3}$ IWAKI \& CO., Ltd., Tokyo, Japan \\ ${ }^{4}$ Akita Research Institute of Food \& Brewing, Akita, Japan \\ Email: *jun_iwashita@akita-pu.ac.jp
}

How to cite this paper: Iwashita, J., Iguchi, N., Takashima, A., Watanabe, D., Sano, K., Ishikuro, M., Hata, K. and Murata, J. (2017) Citrus jabara Extracts Suppress MUC5AC Mucin Production in Human Lung Epithelial Cells. Advances in Biological Chemistry, 7, 139-150.

https://doi.org/10.4236/abc.2017.73009

Received: May 31, 2017

Accepted: June 26, 2017

Published: June 29, 2017

Copyright $\odot 2017$ by authors and Scientific Research Publishing Inc. This work is licensed under the Creative Commons Attribution International License (CC BY 4.0).

http://creativecommons.org/licenses/by/4.0/

\begin{abstract}
In the human airway, the overproduction of MUC5AC mucin is a key feature of allergic asthma, and it induces airway narrowing and obstruction. The production of MUC5AC is regulated by several signals, but the mechanism is not completely understood. We investigated the effect of jabara, a citrus containing abundant flavonoids, on the regulation of MUC5AC production. When NCI-H292 human airway epithelial cells were cultured with jabara extracts, we found that the expression of Periodic acid-schiff stained mucin was suppressed with downregulated MUC5AC production. In human primary airway cells derived from asthmatic patients, MUC5AC production was also suppressed by jabara extracts. The treatment of cells with jabara extracts decreased ERK activation in NCI-H292 and in primary cells. These results show that jabara extracts contain some factors that suppress MUC5AC production and ERK activity and suggest that it will be useful for relieving asthma.
\end{abstract}

\section{Keywords}

MUC5AC, Mucin, Citrus jabara, ERK

\section{Introduction}

In human airways, the mucus layer acts as a protective barrier against foreign irritants and is indispensable in primary host defense. In patients with asthma or chronic obstructive pulmonary disease (COPD), hypersecretion of airway mucus is a hallmark feature. It induces airway narrowing and disease exacerbation [1] [2]. Hence, regulation of mucus production is important in the treatment of asthma. The major constituents of mucus are mucins, which are large, glycosy- 
lated proteins with tandemly repeating sequences that are rich in serine and threonine. Mucins are produced by goblet cells or submucosal glands in the airway epithelia [3].

To date, almost 20 different subfamily mucin genes have been identified. MUC1, 2, 4, 5AC, 5B, 7, 8, and 13 are expressed at the messenger RNA level in human airways [4]. MUC5B and MUC5AC are the principal gel-forming mucins in the mucus layer of a normal airway. In asthma or COPD patients, overproduction of MUC5AC mucin in the airway is a major feature [5] [6] [7] [8].

Mucus production, including MUC5AC production, is regulated by parasympathetic nervous stimulation [9]. Numerous studies have revealed the regulatory system of mucin production in vivo and in vitro [5]. Many studies have described the regulation of MUC5AC expression in airway epithelial cells as a target for asthma treatment. Bacterial inflammation in the airway induces morphological and proliferative changes in goblet cells and mucus hypersecretion. The main inducers of bacterial inflammation are lipopolysaccharides (LPSs) [10] [11]. LPSs have been shown to upregulate the levels of expression of MUC5AC mRNA (by 2.4 times) in HT-29 goblet cells in vitro. Several proinflammatory cytokines, namely, IL-1 $\beta$, IL-6, and IL-17, upregulate MUC5AC expression in airway epithelial cells [12] [13]. Numerous signals that induce an increase of MUC5AC are mediated by the activation of epidermal growth factor (EGF) receptors [14] [15]. EGF receptors activate the ERK pathway and increase the level of NF- $\kappa$ B or Sp1 transcription factor, followed by the upregulation of MUC5AC [16]. There are reports that E-cadherin, a cell-cell adhesion molecule, inhibits mucin production by acting through EGF receptors in coarse-cultured human colon cells [17]. We previously reported that certain ECM components are involved in the regulation of MUC5AC production. It was found to be upregulated on laminin and on Matrigel, a complex of ECM components including collagens and laminin, whereas it was downregulated on type IV collagen in NCI-H292 human airway epithelial cells [18].

Some studies have revealed that certain flavonoids inhibit the activation of mast cells and suppress allergic diseases such as asthma, atopic dermatitis, and cedar pollinosis [19]. Japanese cedar pollinosis caused by Japanese cedar pollen is a common disease in Japan, and the number of patients with it has significantly increased. It was reported that the condition of patients with Japanese cedar pollinosis was improved by Citrus jabara juice intake [20]. Jabara (scientific name, Citrus jabara) belongs to the Rutaceae family and contains abundant narirutin flavonoids from HPLC analysis [21]. Some flavonoids have been reported to suppress allergic asthma. For example, the flavonoid fisetin attenuated OVAinduced mRNA expression of adhesion molecules, chitinase, IL-17, IL-33, and MUC5AC in lung tissue [22] [23]. In addition, the flavonoids narirutin and naringen inhibited the increases of OVA-induced IL-4 cytokine and IgE airway inflammation in an allergic murine model [24] [25].

In this study, we investigated a new regulatory mechanism of MUC5AC production by jabara extracts in human cells. Our results suggest that jabara extracts 
have suppressive functions in the regulation of MUC5AC production in the human airway cell line NCI-H292 and asthmatic primary airway cells.

\section{Materials and Methods}

\subsection{Cell Culture}

Human airway cancer cell line NCI-H292 was purchased from the American Type Culture Collection (Manassas, VA, USA). NCI-H292 cells were cultured in RPMI-1640 (Sigma-Aldrich, Tokyo, Japan) supplemented with 10\% fetal bovine serum (FBS, Cansera International, Etobicoke, Ontario, Canada), 100 units $/ \mathrm{mL}$ of penicillin (Gibco Oriental, Tokyo, Japan), and $100 \mu \mathrm{g} / \mathrm{mL}$ streptomycin (Gibco Oriental) in a $5 \% \mathrm{CO}_{2}$ incubator at $37^{\circ} \mathrm{C}$. Adherent cells were subcultured every 3 - 4 days by treatment with a trypsin-EDTA solution (Gibco Oriental).

Human Airway Epithelia consisting of primary epithelial cells, MucilAir (EP03MD, Epithelix Sàrl, Geneva, Switzerland) is a 3D model of differentiated human epithelium. The MucilAir primary cells were maintained according to the manufacturer's protocol. In brief, the airway primary cells derived from asthmatic patients were cultured at the air-liquid interface in $700 \mu \mathrm{L}$ of culture medium in cell culture inserts. The cells were maintained in a 5\% $\mathrm{CO} 2$ incubator at $37^{\circ} \mathrm{C}$ at the air-liquid interface with fresh medium replaced every 3 days.

\subsection{Reagents}

Jabara $(1.0 \mathrm{~g})$ were extracted in 50\% (W/V) ethanol, and the extracts were collected by centrifugation. The water extract was dried by evaporation. The extraction procedure yielded $555.7 \mathrm{mg}$ of the ethanol extract. $100 \mathrm{mg}$ of jabara extracts was dissolved in $1 \mathrm{ml}$ of ethanol and stored at $-20^{\circ} \mathrm{C}$ until required. The same concentration of ethanol was added to the controls. LPS (Wako, Tokyo, Japan) was dissolved at $0.5 \mathrm{mg} / \mathrm{ml}$ in DMSO. Resazurin (Funakoshi, Tokyo, Japan) was prepared as an aqueous stock solution $(4 \mathrm{mM})$ in distilled water, sterilized by membrane filtration, and stored at $-20^{\circ} \mathrm{C}$ until required.

\subsection{MUC5AC Protein Assay}

NCI-H292 cells without or with jabara extracts were washed once with culture medium and suspended in the medium by means of syringe with a $26 \mathrm{G}$ needle to create a single-cell suspension. Diluted cells $\left(1 \times 10^{4}\right.$ cells per $\left.100 \mu \mathrm{L}\right)$ were added to the wells of 96 -well plate and incubated at $37^{\circ} \mathrm{C}$ without or with LPS and jabara extracts. After removal and storage of the culture media $(100 \mu \mathrm{L})$, the cells were harvested by lysis in $100 \mu \mathrm{L}$ of Tris-buffered saline (TBS; $100 \mathrm{mM} \mathrm{NaCl}$ and $10 \mathrm{mM}$ Tris $\mathrm{pH} 7.5$ ) containing $0.1 \%$ SDS at the indicated time points. A total of $40 \mu \mathrm{L}\left(4 \times 10^{3}\right.$ cells $)$ of the sample was blotted onto an Immobilon membrane (Millipore, Bedford, MA, USA) by Dot Blot Hybridization Manifold (48 wells; SCIE-PLAS, Cambridge, UK). The membrane was treated with $4 \%$ skim milk (Gibco Oriental) in $0.1 \%$ tween 20-TBS (TBS-T) for $12 \mathrm{~h}$ at $4^{\circ} \mathrm{C}$, and then incubated with mouse anti-human MUC5AC antibody (1:2000 in 4\% skim milk, MS145-P1, Thermo Scientific, Kanagawa, Japan) for $1 \mathrm{~h}$. The membrane was 
washed five times for 5 min each with TBS-T and then incubated with rabbit anti-mouse IgG $(\mathrm{H}+\mathrm{L})(1: 2000$ in $4 \%$ skim milk, NA931V, GE Healthcare, Buckinghamshire, UK) for $1 \mathrm{~h}$. After washing the membrane for five times, enzyme reactions were detected with a Luminata Forte western HRP substrate (WBLUF0500, Millipore) and a Chemidoc image analyzer (Biorad, Tokyo, Japan). Mucilair cells, human primary cells, were cultured in $500 \mu \mathrm{L}$ of culture media for $1 \mathrm{~h}$ without and with jabara extracts, and culture media were sampled. The cells were harvested by lysis in $100 \mu \mathrm{L}$ of Tris-buffered saline containing $0.1 \%$ SDS. A total of $20 \mu \mathrm{L}$ of the sample was analyzed using the mucin protein assay to detect the levels of MUC5AC protein.

\subsection{Western Blot Analysis}

The treated NCI-H292 cells and primary cells were cultured on the plates were lysed in a conventional SDS sample buffer (62.5 mM Tris, $10 \%$ glycerol, $2 \%$ SDS, $0.01 \%$ bromophenol blue, $\mathrm{pH} 6.8$ ). The samples were electrophoresed on $10 \%$ of acrylamide gels with a CM-1005 gel apparatus (Cima Biotech, Tokyo, Japan), and then blotted onto a Hybond ECL nitrocellulose membrane (GE Healthcare) with a Trans blot SD cell (Biorad). The membrane was treated with $4 \%$ skim milk (Gibco Oriental) in TBS-T ( $0.1 \%$ tween-20, $150 \mathrm{mM} \mathrm{NaCl}$ and $10 \mathrm{mM}$ Tris $\mathrm{pH}$ 7.5) for $12 \mathrm{~h}$ at $4^{\circ} \mathrm{C}$ and then incubated with a rabbit p-ERK $1 / 2$ (Thr 202) (sc-101760, SANTA CRUZ BIOTECHNOLOGY, CA, USA) and a mouse total ERK antibody (SIGMA, Tokyo, Japan) at a dilution of 1:2000 in 4\% skim milk for $12 \mathrm{~h}$ at $4^{\circ} \mathrm{C}$. The membrane was washed five times for $5 \mathrm{~min}$ each with TBS-T and then incubated with an anti-rabbit IgG conjugated with horseradish peroxidase (W4018, Promega, Madison, WI, USA) or an anti-mouse IgG conjugated with horseradish peroxidase (W4028, Promega) at a dilution of 1:2000 in $4 \%$ skim milk for $1 \mathrm{~h}$. After washing the membrane for five times, the enzyme reaction was detected with a Luminata Forte western HRP substrate (WBLUF0500, Millipore) and a Chemidoc image analyzer (Biorad, Tokyo, Japan). After detection, a blot membrane was incubated with Restore Western blot Stripping buffer (21059, Thermo Scientific, Rockford, IL, USA) for $15 \mathrm{~min}$ at room temperature with shaking. The membrane was washed five times for 5 min each with TBS-T and then treated with $4 \%$ skim milk (Gibco Oriental) in TBS-T for $12 \mathrm{~h}$ at $4^{\circ} \mathrm{C}$ for reblocking.

\subsection{Cell Proliferation Assay}

Cell proliferation was assessed by a Cell Counting Kit-8 (Dojindo, Kumamoto, Japan). NCI-H292 cells $\left(1 \times 10^{4}\right.$ cells in $\left.0.1 \mathrm{~mL}\right)$ were cultured on a 96-well plate (Sumilon, Tokyo, Japan) at $37^{\circ} \mathrm{C}$. The reagent of the kit $(0.01 \mathrm{~mL})$ was added to each well, and then the plate was incubated for $2 \mathrm{~h}$ at $37^{\circ} \mathrm{C}$. Cell growth was assessed by measuring the absorbance at $450 \mathrm{~nm}$ with a microplate spectrophotometer Benchmark plus (BioRad). In Mucilair, a human lung primary cells, chambers were incubated with $100 \mu \mathrm{L}$ of $6 \mu \mathrm{M}$ resazurin at $37^{\circ} \mathrm{C}$ for $1 \mathrm{~h}$ without and with $1 \mathrm{mg} / \mathrm{ml}$ of jabara extracts, and the cell growth was assessed by measuring 
the absorbance at $570 \mathrm{~nm}$ with a microplate spectrophotometer Benchmark plus (BioRad).

\subsection{Periodic Acid-Schiff (PAS) Staining}

NCI-H292 cells $\left(3 \times 10^{4}\right)$ were precultured in 24 -well plates $(1 \mathrm{ml})$ for $12 \mathrm{~h}$, and subsequently incubated without and with $50 \mu \mathrm{g} / \mathrm{ml}$ of LPS, and LPS plus 100 $\mu \mathrm{g} / \mathrm{ml}$ jabara extract. PAS-positive cells were visualized as follows. Cells were fixed with ethanol-acetic acid (3:1), washed with distilled water twice, and then treated with $0.5 \%$ PAS reagent (Wako) followed by $0.6 \%$ sodium metabisulfite (Wako) containing $0.05 \mathrm{~N} \mathrm{HCl}$ (Wako).

\subsection{Statistics}

Analysis of variance (ANOVA) was used for comparisons among more than two groups. For other statistics, Student's t-test was performed. ${ }^{*} \mathrm{p}<0.05$ was considered significant.

\section{Results}

MUC5AC production was downregulated by jabara extracts in NCI-H292 cells.

We first investigated the effect of jabara extracts on cell proliferation. The addition of $2.0 \mathrm{mg} / \mathrm{mL}$ jabara extracts to NCI-H292 cells induced inhibitory effects on cell proliferation; in order to remove the influence of growth inhibitory effects of jabara extracts, we added $1.0 \mathrm{mg} / \mathrm{mL}$ jabara extracts to cells in further experiments (Figure 1(a)). LPS is a representative bacterial inducer of MUC5AC production. We treated NCI-H292 cells with LPS to induce MUC5AC overproduction. The NCI-H292 human airway epithelial cell line was seeded in plates and cultured without and with LPS and jabara extracts for $48 \mathrm{~h}$.

Cell proliferation was not affected significantly by LPS or jabara extracts in NCI-H292 cells cultured for $48 \mathrm{~h}$ and in primary cells cultured for one hour (Figure 1(b), Figure 1(c)). The PAS stain stains glycoproteins, such as mucin proteins, in mucus-producing cells. In NCI-H292 cells cultured without and with LPS or jabara extracts for $48 \mathrm{~h}$, mucin glycoproteins were detected by PAS staining. The PAS-stained glycoproteins were increased in cells that were cultured with LPS compared with those in control cells. The increase in PAS-stained mucin by LPS treatment was decreased significantly by jabara extracts (Figure 2). These results suggest that jabara extracts suppress the increase of mucin. Next, the production of MUC5AC protein was examined by immunoblotting with specific antibodies. We performed a quantitative determination of MUC5AC protein in cells and in culture medium separately in NCI-H292 cells. The content of MUC5AC in cells was upregulated by LPS and downregulated in LPS-stimulated or unstimulated cells cultured with jabara extracts (Figure 3). The secreted MUC5AC production in culture medium was also downregulated in LPS-stimulated or unstimulated cells cultured with jabara extracts (Figure 3). The addition of $0.5 \mathrm{mg} / \mathrm{mL}$ jabara extracts to cells also suppressed the MUC5AC production (data not shown). 
MUC5AC production was downregulated by jabara extracts in asthmatic primary airway cells.

The primary airway cells from human asthmatic patients constitutively produce abundant MUC5AC protein. We thus tested the effect of jabara extracts in human primary cells. Asthmatic primary airway cells were 3D cultured in chambers without and with jabara extracts for one hour. The MUC5AC in cells and in culture medium was sampled and its level was evaluated. The MUC5AC level was inhibited by jabara extracts in primary cells (Figure 4).

ERK activity was downregulated by jabara extracts in NCI-H292 and in primary cells.

(a) $\mathrm{NCl}-\mathrm{H} 292$

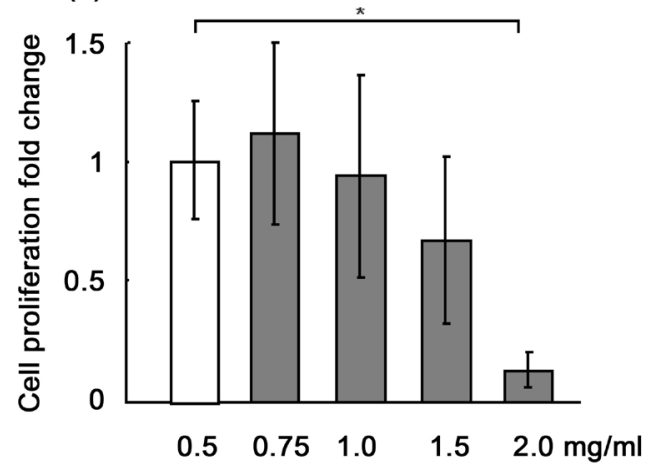

(b)

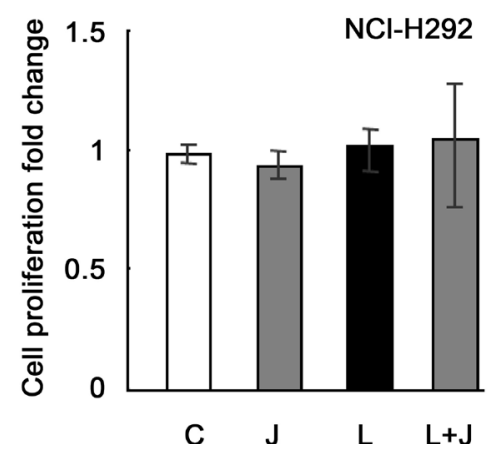

(c)

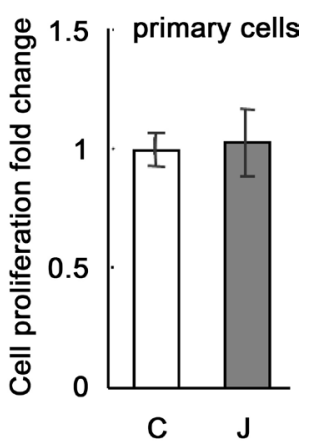

Figure 1. Evaluation of proliferation levels of NCI-H292 cells and primary cells treated with jabara extracts. (a) NCI-H292 cells $\left(1 \times 10^{4}\right.$ cells/well $)$ were cultured in 96-well plates for $48 \mathrm{~h}$. Cells were cultured with jabara extracts in $0-2 \mathrm{mg} / \mathrm{mL}$ jabara extracts and measured for their cell proliferation level using a cell counting kit. Fold changes were based on the level of cells cultured without jabara extracts (mean $\pm \mathrm{SD}, \mathrm{n}=5$, one-way ANOVA); (b) NCI-H292 cells $\left(1 \times 10^{4}\right.$ cells/well) were cultured in 96-well plates for $48 \mathrm{~h}$. Control cells (C), cells cultured with jabara extracts (J), cells cultured with LPS (L), and cells cultured with LPS and jabara extracts $(\mathrm{L}+\mathrm{J})$ were measured for their cell proliferation level with a cell counting kit. Fold changes were based on the level of control cells (mean $\pm \mathrm{SD}, \mathrm{n}=5$, one-way ANOVA); (c) The human primary cells, Mucilair (six wells), were cultured for $1 \mathrm{~h}$. Control cells (C) and cells cultured with jabara extracts (J) were measured for their cell proliferation level. Fold changes were based on the level of control cells (mean $\pm S D, n=6$, two-tailed Student's $t$ test). The final concentration of jabara extracts was $1 \mathrm{mg} / \mathrm{mL}$, for Figure $1(\mathrm{~b})$ and Figure $1(\mathrm{c})$. The cells were cultured with the same final concentrations of ethanol and DMSO. ${ }^{*} \mathrm{p}<0.05$. The representative results of two independent experiments are shown. 


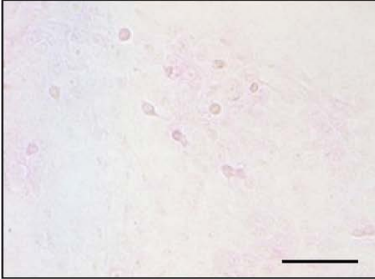

C

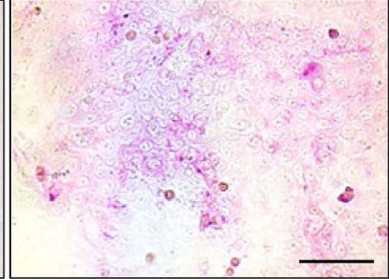

L

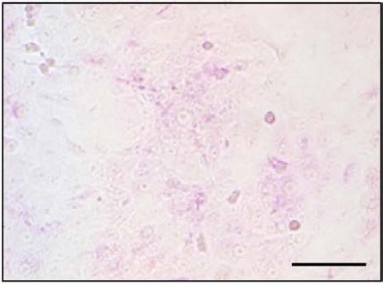

$L+J$

Figure 2. PAS staining of NCI-H292 cells cultured on LPS and jabara extracts. A, NCI-H292 cells $\left(1 \times 10^{4}\right.$ cells/well $)$ were cultured with or without LPS and jabara extracts in a 96-well plate for $48 \mathrm{~h}$. The cells were stained with PAS. The results of control cells (C), cells cultured with LPS (L), and cells cultured with LPS and jabara extracts ( $\mathrm{L}+\mathrm{J})$ are shown. The cells were cultured with the same final concentrations of ethanol and DMSO. Black bars indicate $200 \mu \mathrm{m}$.

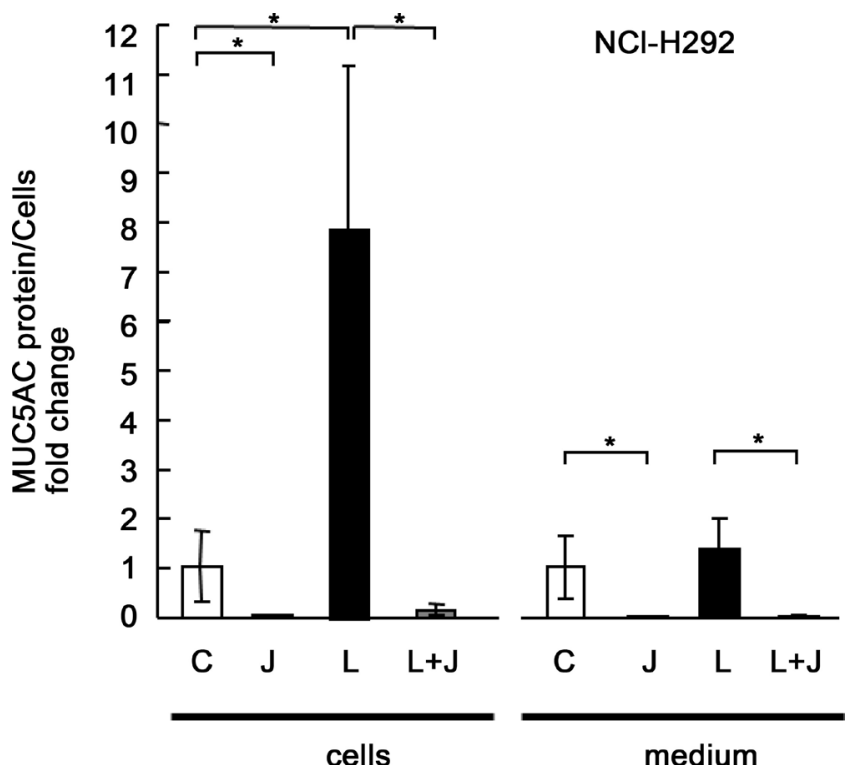

Figure 3. Effects of jabara extracts on the regulation of MUC5AC production in NCI-H292 cells. NCI-H292 cells $\left(1 \times 10^{4}\right.$ cells/well $)$ were cultured in 96 -well plates for 48 $\mathrm{h}$ and cells (cells) and culture media (medium) were sampled. The samples were analyzed using the mucin protein assay to detect the levels of MUC5AC protein. Control cells (C), cells cultured with jabara extracts (J), cells cultured with LPS (L), and cells cultured with LPS and jabara extracts $(\mathrm{L}+\mathrm{J})$ were measured for their cell proliferation level with a cell counting kit. Fold changes were based on the level of control cells (mean $\pm S D, n=5$, one-way ANOVA). The cells were cultured with the same final concentrations of ethanol and DMSO. ${ }^{*} \mathrm{p}<0.05$ (ANOVA). The representative results of three independent experiments are shown.

The ERK pathway is a common activator of MUC5AC production, which is upregulated by LPS. We investigated ERK activity in cells treated with jabara extracts by western blot analysis in NCI-H292 and in primary cells. The phosphorylation and activation of ERK were upregulated by LPS in NCI-H292 cells (Figure 5). The ERK activity was downregulated by jabara extracts in NCI-H292 and in primary cells (Figure 5). These results suggest that jabara extracts inhibit ERK activity in cells and suppress MUC5AC production. 

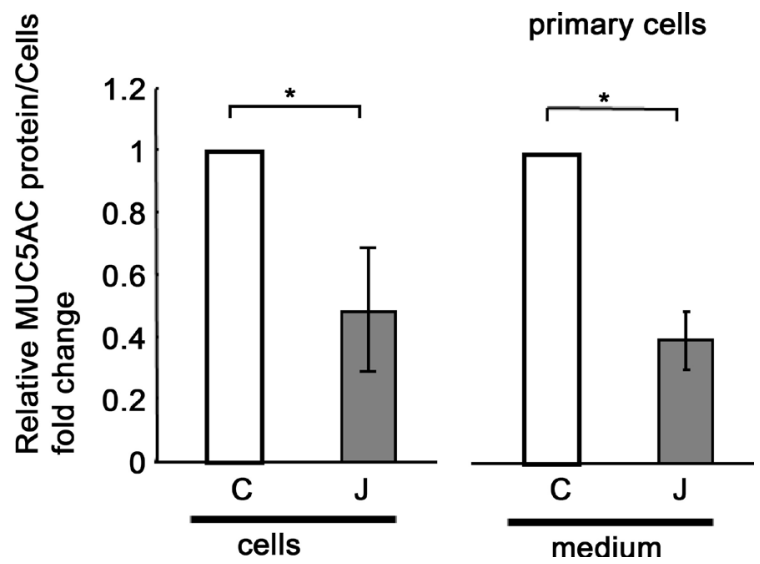

Figure 4. Effects of jabara extracts on the regulation of MUC5AC production in primary cells. Mucilair cells, human primary cells, were cultured for $1 \mathrm{~h}$ without and with jabara extracts and cells (cells) and culture media (medium) were sampled. The samples were analyzed using the mucin protein assay to detect the levels of MUC5AC protein. Control cells $(\mathrm{C})$, cells cultured with jabara extract (J) were measured their MUC5AC protein levels and cell proliferation level. The cells were cultured with the same final concentration of ethanol. Fold changes were based on the level of control cells (mean $\pm S D, n=6$, one-way ANOVA). ${ }^{*} \mathrm{p}<0.05$ (ANOVA). The representative results of three independent experiments are shown.

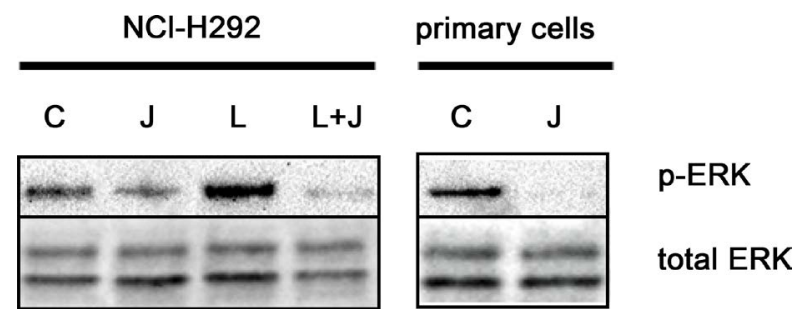

Figure 5. Evaluation of the ERK activity in NCI-H292 cells and primary cells treated with jabara extracts. NCI-H292 cells $\left(1 \times 10^{4}\right.$ cells/well $)$ were cultured in 96-well plates for $48 \mathrm{~h}$ and then sampled. The samples were evaluated for their phosphorylated and activated ERK (p-ERK) levels and total ERK levels. The ERK levels of control cells (C), cells cultured with jabara extracts (J), cells cultured with LPS (L), and cells cultured with LPS and jabara extracts $(\mathrm{L}+\mathrm{J})$ are shown. The human primary cells, Mucilair (six wells), were cultured for $1 \mathrm{~h}$ without and with jabara extracts. Control cells (C) and cells cultured with jabara extracts (J) were sampled. The samples were evaluated for their phosphorylated and activated ERK (p-ERK) levels and total ERK levels. The cells were cultured with the same final concentrations of ethanol and DMSO. The representative results of three independent experiments are shown.

\section{Discussion}

Asthma and COPD are chronic diseases featuring inflamed airway and MUC5AC overproduction. Several reports have described that citrus may also worsen asthma symptoms. Citrus acidic stimulation may be a trigger of allergies in airway and lung [26]. On the other hand, numerous citrus flavonoids were reported to be useful for asthma remedies [22] [23] [24] [25]. As an explanation of this contradiction, citrus contains multiple factors that trigger asthma or COPD but is also useful in the treatment of chronic diseases. Identification of the active ingredients, such as narirutin flavonoids, in jabara extracts would be useful for re- 
lieving asthma symptoms. Further studies about natural polyphenol content and antioxidant activity of jabara extract are needed in order to analyze the active ingredient of jabara. Another possibility is that the jabara flavonoids may function in a concentration dependent manner. We will examine the concentration-dependent effect of jabara extracts on MUC5AC production in NCI-H292 and in primary cells.

In this study, we found that jabara extracts suppressed ERK activity and MUC5AC production in NCI-H292 cells and in human primary airway cells. The overproduction of MUC5AC induced by LPS in cells and in medium was suppressed by jabara extracts (Figure 3). The content of MUC5AC in cells induced by LPS was about 6 folds compared in the medium and both were suppressed by jabara extracts (Figure 3). This result suggests that LPS mainly induces the overproduction of intra cellular and cell attached MUC5AC and the overproduction was suppressed by jabara extracts. These results suggest that jabara extract suppresses MUC5AC production by way of inhibition of ERK activity in airway cells. The ERK pathway increases the function of NF- $\kappa \mathrm{B}$ or Sp1 transcription factor, which are common activators of MUC5AC production [16]. Our results suggest that jabara extracts might inhibit ERK, NF- $\kappa$ B or Sp1 activity and suppress MUC5AC production (Figure 6). These findings suggest a novel approach for treating asthma or COPD by suppressing mucus overproduction in the airways.

\section{Conclusion}

MUC5AC production and ERK activity were suppressed by jabara extracts in human lung epithelial NCI-H292 cells and in asthmatic primary cells. These results may be useful for treating asthma or COPD using jabara extracts.

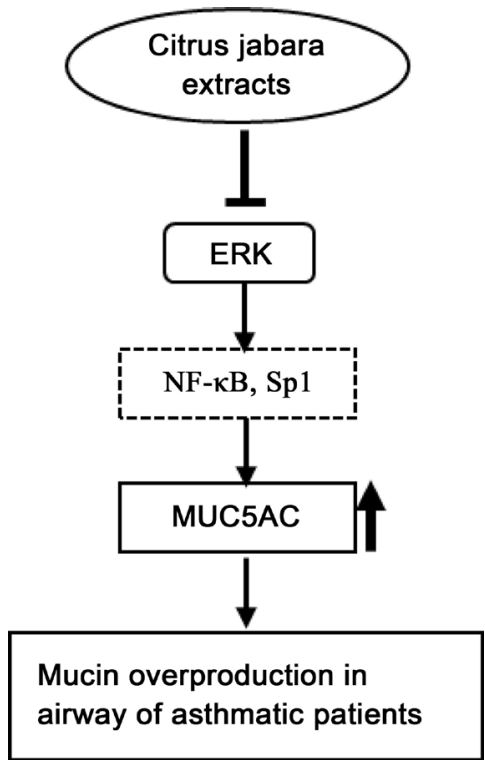

Figure 6. Model of suppression of MUC5AC production by jabara extracts by inhibition of the ERK signaling pathway. Schematic representation of the molecular pathways directing MUC5AC production by the ERK intervening pathway. 


\section{Acknowledgements}

This work was supported in part by Akita Prefectural University President's Research Project Fund. This work was also supported in part by Akita Prefectural No-sho-ko Support Fund. The authors would like to thank Enago (http://www.enago.jp) for the English language review.

\section{Conflict of Interest}

Authors have no conflict of interest.

\section{References}

[1] Aikawa, T., Shimura, S., Sasaki, H., Ebina, M. and Takishima, T. (1992) Marked Goblet Cell Hyperplasia with Mucus Accumulation in the Airways of Patients Who Died of Severe Acute Asthma Attack. Chest, 101, 916-921. https://doi.org/10.1378/chest.101.4.916

[2] Vestbo, J. (2002) Epidemiological Studies in Mucus Hypersecretion. Novartis Foundation Symposium, 248, 3-12, 277-282. https://doi.org/10.1002/0470860790.ch2

[3] Rogers, D.F. (2003) The Airway Goblet Cell. The International Journal of Biochemistry \& Cell Biology, 35, 1-6. https://doi.org/10.1016/S1357-2725(02)00083-3

[4] Voynow, J.A., Gendler, S.J. and Rose, M.C. (2006) Regulation of Mucin Genes in Chronic Inflammatory Airway Diseases. American Journal of Respiratory Cell and Molecular Biology, 34, 661-665. https://doi.org/10.1165/rcmb.2006-0035SF

[5] Rose, M.C. and Voynow, J.A. (2006) Respiratory Tract Mucin Genes and Mucin Glycoproteins in Health and Disease. Physiological reviews, 86, 245-278. https://doi.org/10.1152/physrev.00010.2005

[6] Fahy, J.V. (2002) Goblet Cell and Mucin Gene Abnormalities in Asthma. Chest, 122, 320S-326S. https://doi.org/10.1378/chest.122.6_suppl.320S

[7] Rogers, D.F. (2004) Airway Mucus Hypersecretion in Asthma: An Undervalued Pathology? Current Opinion in Pharmacology, 4, 241-250.

https://doi.org/10.1016/j.coph.2004.01.011

[8] Wang, K., Wen, F.Q. and Xu, D. (2008) Mucus Hypersecretion in the Airway. Chinese Medical Journal, 121, 649-652.

[9] Perez-Vilar, J., Sheehan, J.K. and Randell, S.H. (2003) Making More MUCS. American Journal of Respiratory Cell and Molecular Biology, 28, 267-270.

https://doi.org/10.1165/rcmb.F262

[10] Smirnova, M.G., Guo, L., Birchall, J.P. and Pearson, J.P. (2003) LPS Up-Regulates Mucin and Cytokine mRNA Expression and Stimulates Mucin and Cytokine Secretion in Goblet Cells. Cellular Immunology, 221, 42-49. https://doi.org/10.1016/S0008-8749(03)00059-5

[11] Mohamed, F.B., Garcia-Verdugo, I., Medina, M., Balloy, V., Chignard, M., Ramphal, R. and Touqui, L. (2012) A Crucial Role of Flagellin in the Induction of Airway Mucus Production by Pseudomonas aeruginosa. PLoS ONE, 7, e39888. https://doi.org/10.1371/journal.pone.0039888

[12] Chen, Y., Thai, P., Zhao, Y.H., Ho, Y.S., DeSouza, M.M. and Wu, R. (2003) Stimulation of Airway Mucin Gene Expression by Interleukin (IL)-17 through IL-6 Paracrine/Autocrine Loop. The Journal of Biological Chemistry, 278, 17036-17043. https://doi.org/10.1074/jbc.M210429200

[13] Song, K.S., Lee, W.J., Chung, K.C., Koo, J.S., Yang, E.J., Choi, J.Y. and Yoon, J.H. 
(2003) Interleukin-1 Beta and Tumor Necrosis Factor-Alpha Induce MUC5AC Overexpression through a Mechanism Involving ERK/p38 Mitogen-Activated Protein Kinases-MSK1-CREB Activation in Human Airway Epithelial Cells. The Journal of Biological Chemistry, 278, 23243-23250.

https://doi.org/10.1074/jbc.M300096200

[14] Takeyama, K., Dabbagh, K., Jeong Shim, J., Dao-Pick, T., Ueki, I.F. and Nadel, J.A. (2000) Oxidative Stress Causes Mucin Synthesis via Transactivation of Epidermal Growth Factor Receptor: Role of Neutrophils. Journal of Immunology, 164, 1546 1552.

[15] Basbaum, C., Li, D., Gensch, E., Gallup, M. and Lemjabbar, H. (2002) Mechanisms by Which Gram-Positive Bacteria and Tobacco Smoke Stimulate Mucin Induction through the Epidermal Growth Factor Receptor (EGFR). In: Chadwick, D.J. and Goode, J.A., Eds., Mucus Hypersecretion in Respiratory Disease: Novartis Foundation Symposium 248, John Wiley \& Sons, Ltd., Chichester, UK, 171-176. https://doi.org/10.1002/0470860790.ch11

[16] Takeyama, K., Dabbagh, K., Lee, H.M., Agusti, C., Lausier, J.A., Ueki, I.F., Grattan, K.M. and Nadel, J.A. (1999) Epidermal Growth Factor System Regulates Mucin Production in Airways. Proceedings of the National Academy of Sciences of the United States of America, 96, 3081-3086. https://doi.org/10.1073/pnas.96.6.3081

[17] Iwashita, J., Ose, K., Ito, H., Murata, J. and Abe, T. (2011) Inhibition of E-Cadherin Dependent Cell-Cell Contact Promotes MUC5AC Mucin Production through the Activation of Epidermal Growth Factor Receptors. Bioscience, Biotechnology, and Biochemistry, 75, 688-693. https://doi.org/10.1271/bbb.100830

[18] Iwashita, J., Yamamoto, T., Sasaki, Y. and Abe, T. (2010) MUC5AC Production Is Downregulated in NCI-H292 Lung Cancer Cells Cultured on Type-IV Collagen. Molecular and Cellular Biochemistry, 337, 65-75. https://doi.org/10.1007/s11010-009-0286-Z

[19] Tanaka, T. (2014) Flavonoids for Allergic Diseases: Present Evidence and Future Perspective. Current Pharmaceutical Design, 20, 879-885. https://doi.org/10.2174/13816128113199990060

[20] Minatoguchi, M., Oono, Y. and Funaguchi, N (2008-2009) Effect of "Jabara" Juice on Symptoms and QOL in Patients with Japanese Cedar Pollinosis. Clinical Immunology \& Allergology, 50, 360-364.

[21] Nakachi, K. (2015) Cultivation of High Performance Hybrid Varieties of Citrus Jabara. In: Research of the Wakayama Prefectural Experiment Stations of Agriculture, Forestry and Fisheries, 9.

[22] Tanaka, T. and Takahashi, R. (2013) Flavonoids and Asthma. Nutrients, 5, 2128 2143. https://doi.org/10.3390/nu5062128

[23] Goh, F.Y., Upton, N., Guan, S., Cheng, C., Shanmugam, M.K., Sethi, G., Leung, B.P. and Wong, W.S. (2012) Fisetin, a Bioactive Flavonol, Attenuates Allergic Airway Inflammation through Negative Regulation of NF-kappaB. European Journal of Pharmacology, 679, 109-116.

[24] Funaguchi, N., Ohno, Y., La, B.L., Asai, T., Yuhgetsu, H., Sawada, M., Takemura, G., Minatoguchi, S., Fujiwara, T. and Fujiwara, H. (2007) Narirutin Inhibits Airway Inflammation in an Allergic Mouse Model. Clinical and Experimental Pharmacology \& Physiology, 34, 766-770. https://doi.org/10.1111/j.1440-1681.2007.04636.x

[25] Xiong, G., Liu, S., Gao, J. and Wang, S. (2016) Naringin Protects Ovalbumin-Induced Airway Inflammation in a Mouse Model of Asthma. Inflammation,39, 891899. https://doi.org/10.1007/s10753-016-0321-7

[26] Kumar, R., Kumari, D., Srivastava, P., Khare, V., Fakhr, H., Arora, N., Gaur, S.N. 
and Singh, B.P. (2010) Identification of IgE-Mediated Food Allergy and Allergens in Older Children and Adults with Asthma and Allergic Rhinitis. The Indian Journal of Chest Diseases \& Allied Sciences, 52, 217-224.

Submit or recommend next manuscript to SCIRP and we will provide best service for you:

Accepting pre-submission inquiries through Email, Facebook, LinkedIn, Twitter, etc. A wide selection of journals (inclusive of 9 subjects, more than 200 journals)

Providing 24-hour high-quality service

User-friendly online submission system

Fair and swift peer-review system

Efficient typesetting and proofreading procedure

Display of the result of downloads and visits, as well as the number of cited articles Maximum dissemination of your research work

Submit your manuscript at: http://papersubmission.scirp.org/

Or contact abc@scirp.org 